\title{
The Effect of Different Plate Condition on Water Absorption Rate of Mineral Wool of Roof Panel
}

\author{
Servan Baran ${ }^{1, *}$, Hadi Abbaszadeh ${ }^{2}$ \\ ${ }^{1,2}$ MS.C. Student, Faculty of civil engineering, Istanbul Technical University, Istanbul, Turkey \\ *Corresponding author
}

\begin{abstract}
In recent years focus in energy dissipation was enhanced significantly and it effects the construction industry and specifically in construction materials. Using roof panel with mineral wool could significantly increase the energy trapped in building. Insulation materials which are used instead of energy dissipation were affected from environmental occurrence such as rain, fire and etc. Moreover, the condition of intended materials and specifically roof panels could affect their performance. In this paper, the effect of three different conditions (a) defected, (b) intact, (c) defected with long eave was demonstrated using water absorption rate of each specimen. Water absorption of each three specimens were measured every 3 hours until 12 hours under rain simulator which was provided for this test both for $3 \%$ and $7 \%$ slop. Weights were measured for both air dried and oven dried and comparison was made among different conditions. One special fully covered intact specimen was provided also and measurements were implemented for this specimen for making better comparison. Results indicate approximately $2.5,82$, and 52 times increase in ultimate water absorption (12 hours) compared oven dried specimen for defected, intact, defected with long eave respectively.
\end{abstract}

Keywords: Mineral wool, Insulation Materials, Mineral wool of roof panels, Water absorption.

\section{Introduction}

In recent years, energy dissipation has gained a great importance in order to have more sustainable environment in construction material industry. European Union indicates that $40 \%$ of total energy consumption spent by building sector and EU points out that the building sector is a growing sector therefore usage of renewable sources and energy savings in the building sector plays key role on reducing greenhouse emissions and energy dependency (Directive 2010/31/EU of the European Parliament and of the Council of 19 May 2010 on the Energy Performance of Buildings). In this area buildings thermal insulation could considerably used as a technique to save more energy in buildings due to both winter heating and summer cooling. While deciding thermal insulation material for building; cost, compression strength, vapor absorption and above all the k-value of the material have to be taken into consideration (Abdou and Budaiwi, 2013). In addition, implementation of thermal insulation materials in buildings could decrease the heat loss; moreover, it significantly increases the amount of stored heat in buildings.

Mineral wool contains high volume of stagnant air which has low thermal conductivity, therefore it can be used as a remarkable thermal insulator, hence mineral wool can prevent convection of heat (EURIMA, 2006). Usage of inorganic insulation materials in building 
sector increased dramatically in last decades. European building insulation market consists $60 \%$ of inorganic fibrous materials such as glass wool and mineral wool (Cabeza, 2010). It is very common to see implementation of fibrous material insulation materials on the exterior walls. Besides there are several methods of using inorganic fibrous insulation materials on the roof systems.

Utilization of mineral wool product on the roof system is not just progress thermal performance of building. Additionally mineral wool is a fire resistant material and it provides a very high level of noise adsorption. Thus, mineral wool product improves acoustic and fire insulation features of material. However, there are some issues which significantly affect the performance of insulation materials such as rain, fire, gale, etc. thus intended materials should be protected from mentioned environmental effects by applying different architectural details. Moisture could dramatically decrease the performance of insulation materials in buildings. Moisture existence in insulation materials could enhance the coefficient of heat transfer and reduce the heat insulation capacity also (Szodrai and Lakatos, 2014), (Lakatos and Kalmár, 2013,A), and (Lakatos and Kalmár, 2013, B).

The volume of porosity could influence the water absorption rate in the way that by increasing the porosity water absorption increases simultaneously (Szodrai and Lakatos 2014), (Zhang et al., 2014), (Babu et al., 2006), and (Wilby et al., 2014). The humidity negative effects could observed primarily on the outer face of building; in addition, the water absorption capability of intended insulation materials could be demonstrated with their absorption isotherm (Szodrai and Lakatos, 2014), (Gnip et al., 2016), (Duskov, 1997), (Kalmár and Csáki, 2011), and (Kalmár and Csáki, 2012).

The existence of moisture may effect physical properties of the construction materials. Water absorption effects the performance of thermal conductivity of mineral wood due to its porous character (Szodrai and Lakatos 2014). If the exterior temperature decreases under $0{ }^{\circ} \mathrm{C}$ the inner moisture may changes its phase and it can transform from liquid phase to solid phase. Due to expansion there would be irreversible defects on the structure of material.

In this paper, the effect of plate condition on the water absorption of mineral wool of roof panels with 3\% and 7\% slop have been investigated and the results was compared and discussed based on different plate condition and slop. 


\section{Experimental work}

Rain simulator was designed and produced in Istanbul Technical University construction material Lab. and was developed to simulate rain both for 3\% and 7\% which is the aim of this paper to find out the water absorption in these slops (see Fig. 1).

\section{Figure 1: Raining simulator setup}

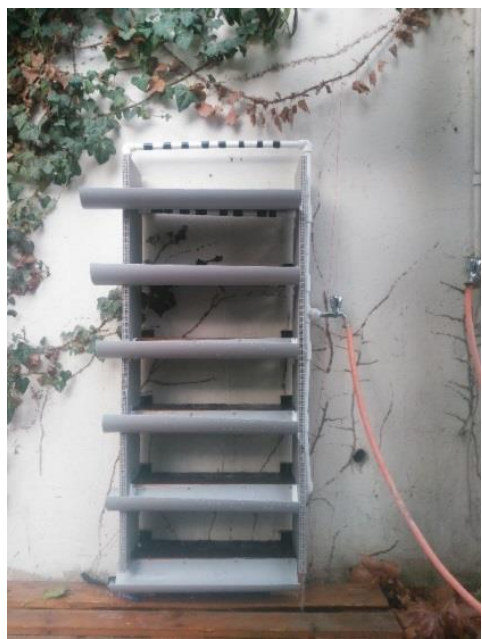

Figure 2. Rain simulator process (with $3 \%$ slop)

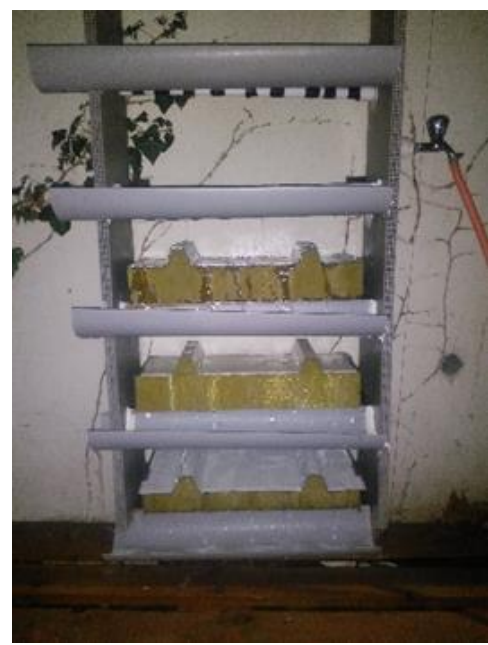

Specimens were provided in three different conditions which observed in Fig. 3. A great part of defected panel was derived from an old building and was cut out for defected specimen (Fig. 3.a). Intact specimen cut out using cutting machine from the products which was provided from related company (see Fig. 3.b). And last sample is defected specimen with long eave which was made using special cutting machine for gaining precise eave (Fig. 2.c).

Figure 3: Panels (a) Defected, (b) Intact, and (c) Defected with long eave

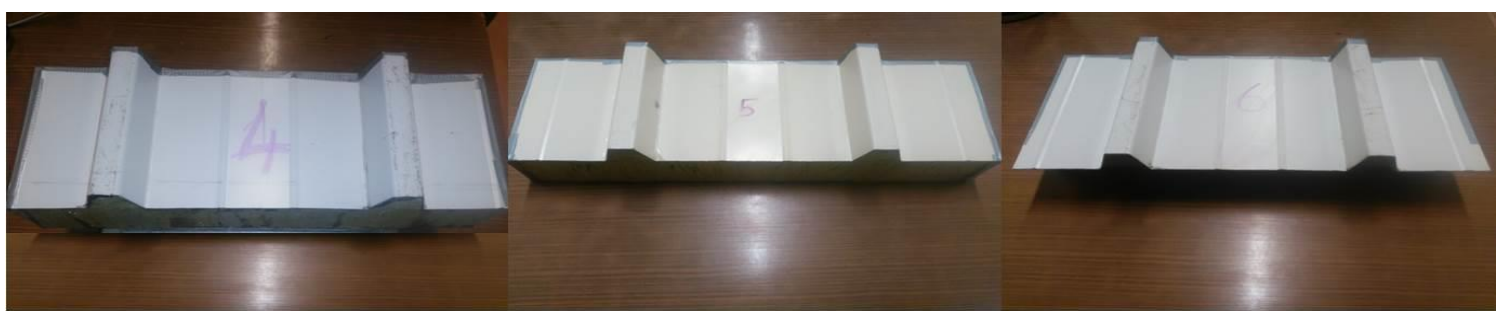

(a)

(b)

(c)

All three specimens was tested using simulator simultaneously for ultimately 12 hours for both $3 \%$ and $7 \%$ slops (see Fig. 2). In addition, in order to measure the water absorption specimens were weighted every 3 hours until 12 hours; air dried and oven dried weights was measured, also.

The oven process was performed using a verticell machine in this research experiment. Specimens were dried using 60 0C for 24 hours simultaneously in a verticell machine in construction material laboratory and then the specimens was weighted. 
Figure 4: Verticell process (consist of all specimens)

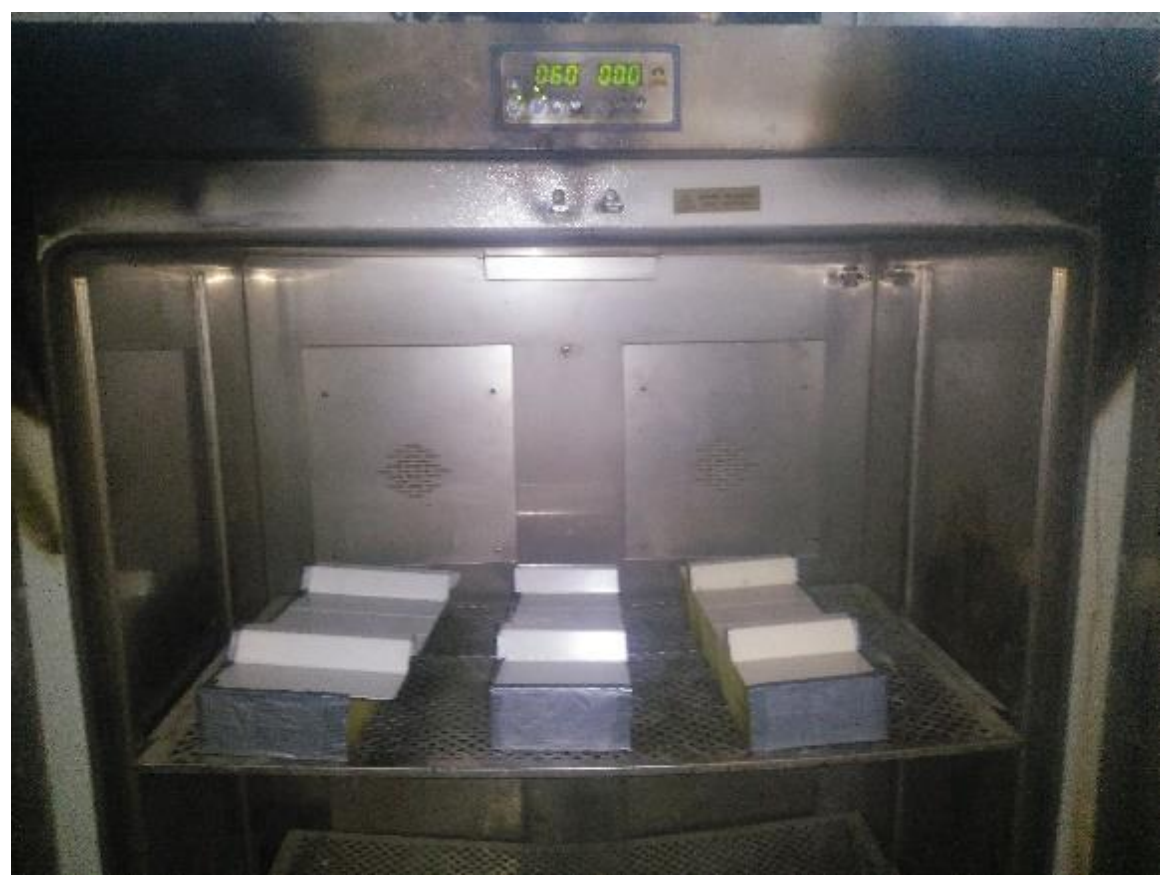

A screwed specimen which was covered completely was tested under rain simulator and oven and weighting process was performed for this special case. Results were for this case shown to make comparison with other types.

\section{Results and discussion}

Weighting process was implemented simultaneously for all specimens and results was shown in Table 1.

Table 1: Weight of samples in different conditions

\begin{tabular}{llllllll}
\hline $\begin{array}{l}\text { Condition } \\
\text { (Slope) }\end{array}$ & Sample type & $\begin{array}{l}\text { OVEN } \\
\text { DRIED } \\
(\mathrm{gr})\end{array}$ & $\begin{array}{l}\text { AIR } \\
\text { DRIED } \\
(\mathrm{gr})\end{array}$ & $\begin{array}{l}3^{\text {rd }} \text { HOUR } \\
(\mathrm{gr})\end{array}$ & $\begin{array}{l}6^{\text {th }} \text { HOUR } \\
(\mathrm{gr})\end{array}$ & $\begin{array}{l}9^{\text {th }} \text { HOUR } \\
(\mathrm{gr})\end{array}$ & $\begin{array}{l}12^{\text {th }} \text { HOUR } \\
(\mathrm{gr})\end{array}$ \\
\hline $3 \%$ & Defected & 1255.6 & 1258 & 1318.3 & 1372.8 & 1412.7 & 1456.6 \\
& Intact & 1086.8 & 1088.7 & 1091.5 & 1091.6 & 1093 & 1095.3 \\
& $\begin{array}{l}\text { Defected with } \\
\text { long eave }\end{array}$ & 1394.7 & 1397.2 & 1405.5 & 1490.7 & 1514 & 1532.1 \\
& $\begin{array}{l}\text { Defected } \\
7 \%\end{array}$ & 1255.6 & 1259.7 & 1314.6 & 1341.8 & 1371.9 & 1400.6 \\
& $\begin{array}{l}\text { Intact } \\
\text { Defected with }\end{array}$ & 1394.7 & 1397 & 1425.8 & 1469.5 & 1528.2 & 1540.7 \\
& $\begin{array}{l}\text { long eave } \\
\text { Solid Screwed } \\
\text { plate }\end{array}$ & 1303.7 & 1305.5 & 1306.7 & 1307.4 & 1307.7 & 1308.4 \\
\hline
\end{tabular}


Table 2: Water absorption by weight results based on oven dried sample (\%)

\begin{tabular}{|c|c|c|c|c|c|c|}
\hline $\begin{array}{l}\text { Condition } \\
\text { (Slope) }\end{array}$ & Sample type & $\begin{array}{l}\text { AIR DRIED } \\
(\%)\end{array}$ & $\begin{array}{l}3^{\text {rd }} \text { HOUR } \\
(\%)\end{array}$ & $\begin{array}{l}6^{\text {th }} \text { HOUR } \\
(\%)\end{array}$ & $\begin{array}{l}9^{\text {th }} \text { HOUR } \\
(\%)\end{array}$ & $\begin{array}{l}12^{\text {th }} \text { HOUR } \\
(\%)\end{array}$ \\
\hline \multirow[t]{3}{*}{$3 \%$} & Defected & 0.19 & 4.99 & 9,33 & 12.51 & 16.01 \\
\hline & Intact & 0.17 & 0.43 & 0.44 & 0.57 & 0.78 \\
\hline & $\begin{array}{l}\text { Defected with } \\
\text { long eave }\end{array}$ & 0.18 & 0.77 & 6.88 & 8.55 & 9.85 \\
\hline \multirow[t]{4}{*}{$7 \%$} & Defected & 0.33 & 4.70 & 6.87 & 9.26 & 11.55 \\
\hline & Intact & 0.17 & 0.35 & 0.50 & 0.62 & 0.79 \\
\hline & $\begin{array}{l}\text { Defected with } \\
\text { long eave }\end{array}$ & 0.16 & 2.23 & 5.36 & 9.57 & 10.47 \\
\hline & $\begin{array}{l}\text { Solid Screwed } \\
\text { plate }\end{array}$ & 0.14 & 0.23 & 0.28 & 0.31 & 0.36 \\
\hline
\end{tabular}

Air dried weights was measured at the beginning of process; however, the other steps was measured every 3 hours and after oven process for oven dried.

Table 2 demonstrates the water absorptions of different specimens in various conditions based on oven dried (completely dried specimen as source) specimens to make comparison between different conditions. Results indicates that there is great difference between intact and defected sample after 12 hours rain test in the case that water absorption of intact specimen was increased to 82 times in 12 hours compared with air dried.

In addition, the water absorption was enhanced 2.5 times in 12 hours compared with air dried; however, this rate is 52 times for defected specimen with long eave for $3 \%$ slop. Thus, it was concluded that using long eave in defected specimen could significantly retrofit the performance and improve the result of defected specimens.

Increasing the slop in rain test to $7 \%$ could significantly reduce the water absorption rate (38\%) compared $3 \%$ slop; however, it has almost no effect on intact and defected with long eave specimen.

Results for special screwed (fully covered intact) specimen was dramatically decrease the amount of water absorption even lower that intact specimens which indicates the importance of covering implementation in roof panels. 
Figure 5: Water absorption (\%) for 3\% slop

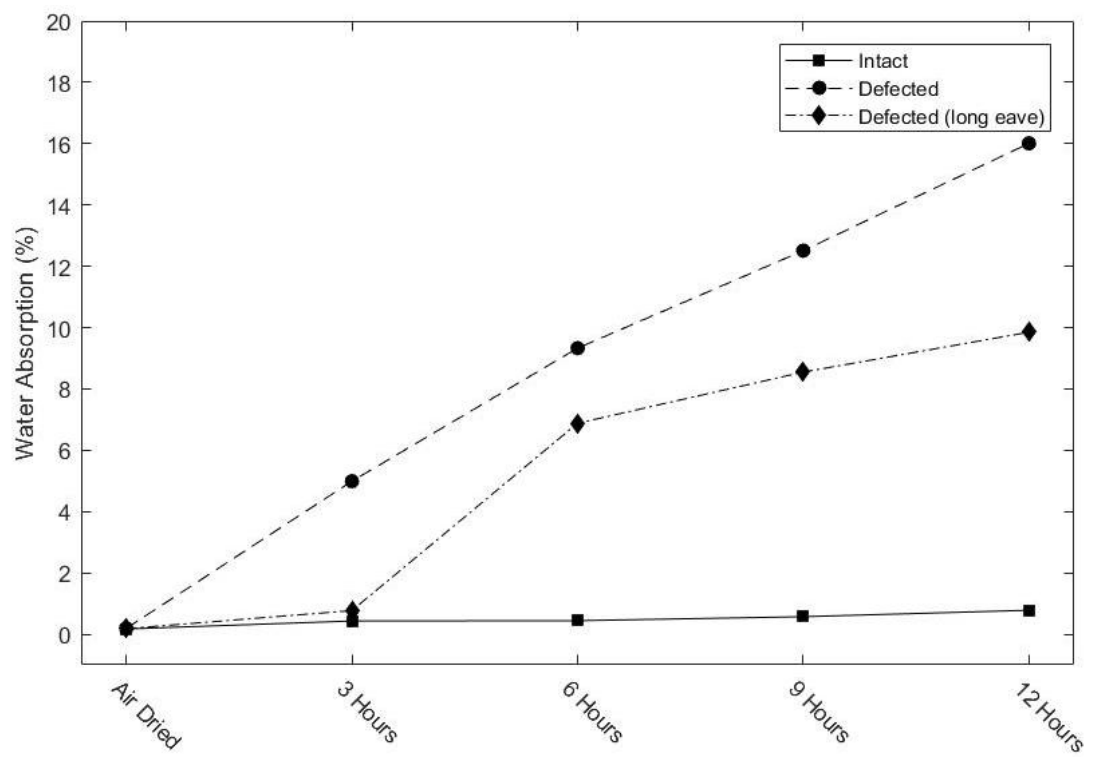

In test by $3 \%$ slop, the intact specimen due to low rate of water absorption continue increasing with very low slop and defected specimen water absorption increases by approximately linear slop. However, defected with long eave specimen demonstrates very small water absorption in first step of measurement (3 hours) and then and increase occur in this specimen. In addition, if only first and last points considered a line that connects these points to each other has a similar slop compared defected specimen but with lower values (see Fig. 5).

Figure 6: Water absorption (\%) for 7\% slop

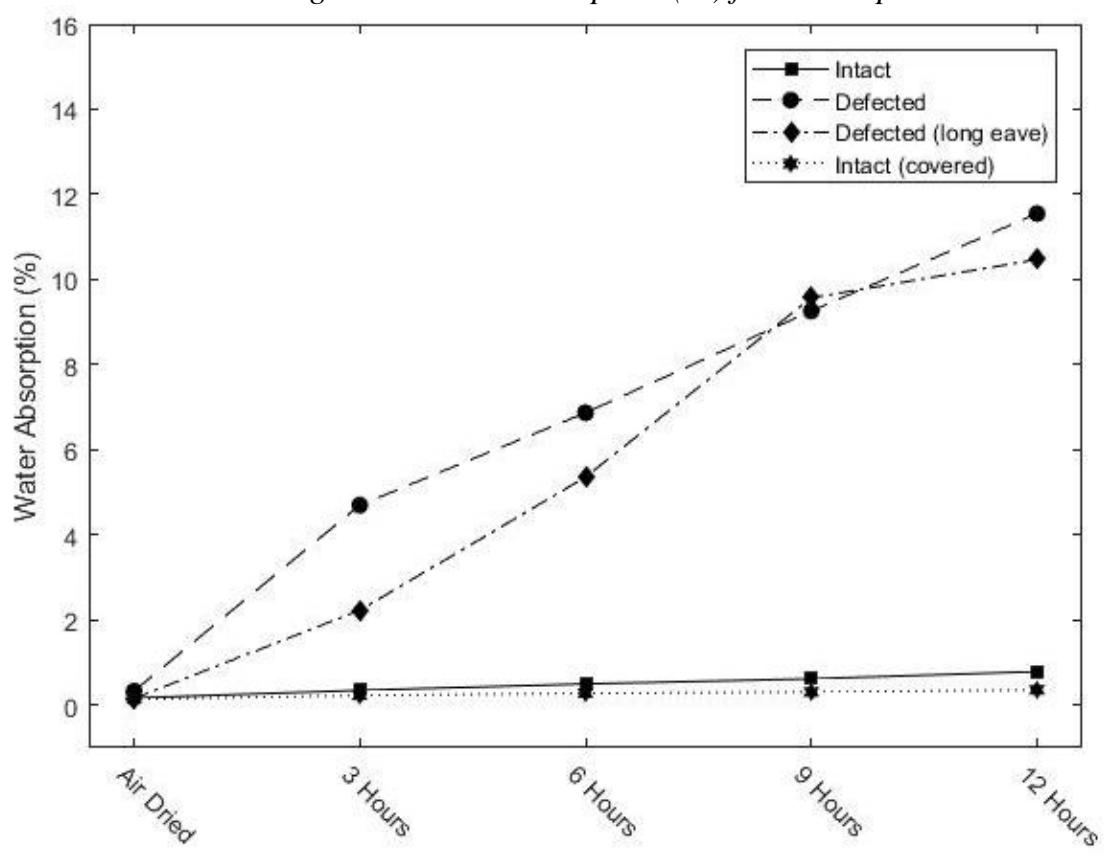

In test with 7\% slop, the intact covered specimen demonstrates almost zero increase during raining simulation process. However, intact, defected, and defected with long eave shows approximately similar behaviour compared $3 \%$ slop (see Fig. 6). 


\section{Conclusion}

The use of insulation material specifically roof panel could significantly increase the saved energy in building. In addition, water absorption due to environmental phenomenon could decrease the workability of roof panel which consist of mineral wool; moreover, use of different conditions could affect mineral would water absorption magnitude.

This paper represent the differences among three conditions consist of intact, defected, defected with long eave in both $3 \%$ and $7 \%$ slops. Results indicate that there is a great difference between intact and defected specimen water absorption value which could be retrofitted using long eave slightly.

Results for one special intact fully covered specimen shows almost zero increase in process of water absorption from its main condition (air-dried).

\section{References}

[1] F. Szodrai, Á. Lakatos, 2014, "MEASUREMENTS OF THE THERMAL CONDUCTIVITIES OF SOME COMMONLY USED INSULATING MATERIALS AFTER WETTING," Environmental Engineering and Management Journal, vol. 13, pp. 2881-2886.

[2] C. Hill, A. Norton, J. Dibdiakova, 2018, "A comparison of the environmental impacts of different categories of insulation materials," Energy and Buildings, vol. 13, pp. 12-20.

[3] A. Lakatos, F. Kalmár, 2013, A, "Analysis of water sorption and thermal conductivity of expanded polystyrene insulation materials," Building Services Engineering Research and Technology, vol. 34, pp. 407-416.

[4] A. Lakatos, F. Kalmár, 2013, B, "Investigation of thickness and density dependence of thermal conductivity of expanded polystyrene insulation materials," Materials and Structures, vol. 46, pp. 1101-1105.

[5] H. Zhang, D. Hu, R. Wang, Y. Zhang, 2014, "Urban energy saving and carbon reduction potential of new types of building materials by recycling coal mining wastes," Environmental Engineering and Management Journal, vol. 13, pp. 135-144.

[6] D. S. Babu, K. G. Babu, W. Tiong Huan, 2006, "Effect of polystyrene aggregate size on strength and moisture migration characteristics of lightweight concrete," Cement \& Concrete Composites, vol. 28, pp. 520-527.

[7] M. R. Wilby, A. B. R. González, F. J. A. Gómez, J. J. Vinagre Díaz, 2014, "Energy efficiency landscapes: An energy efficiency visual tool for supporting decision making in buildings," Environmental Engineering and Management Journal, vol.13, pp. 81-94.

[8] I. Gnip, V. Keršulis, S. Vejjelis, 2016, "Isotherms of water vapor sorption by light inorganic and polymer heatinsulating materials," Journal of Engineering Physics and Thermophysics, vol.79, pp. 40-47.

[9] M. Duskov, 1997, "Materials research on EPS20 and EPS15 under representative conditions in pavement structures," Geotextiles and Geomembranes, vol. 15, pp. 147-181. 
[10] F. Kalmár, I. Csáki, 2011, "Hydraulic aspects of scaling in geothermal energy systems," Environmental Engineering and Management Journal, vol. 8, pp. 1155-1160.

[11] F. Kalmár, I. Csáki, 2012 "Simulation of the internal temperature in the Passol Laboratory," University of Debrecen, International Review of Applied Sciences and Engineering, vol. 3, pp. 63-73.

[12] A. Abdou, I. Budaiwi, 2013, "The variation of thermal conductivity of fibrous insulation materials under different levels of moisture content," Construction and Building Materials, vol. 43, pp. 533-544.

[13] S. Schiavoni, F. D'Alessandro, 2016, F. Bianchi, F. Asdrubali, "Insulation materials for the building sector: A review and comparative analysis," Renewable and Sustainable Energy Reviews, vol. 62, pp. 988-1011.

[14] Directive 2010/31/EU of the European Parliament and of the Council of 19 May 2010 on the Energy Performance of Buildings.

[15] L.F. Cabeza, 2010, A. Castell, M. Medrano, I. Martorell, G. Perez, I. Fernandez, "Experimental study on the performance of insulation materials in Mediterranean construction," Energy and Buildings, vol. 42, pp. 630-636.

[16] EURIMA, 2006, European Insulation Manufacturers Association, Available: www.eurima.org. 